\title{
Millennial-scale climate variability in the American tropics and subtropics
}

Dunia H. Urrego ${ }^{1,2}$, J.P. Bernal ${ }^{3}$, C.M. Chiessi ${ }^{4}$, F.W. Cruz ${ }^{5}$, M.F. Sanchez-Goñi ${ }^{2}$, M. Power ${ }^{6}$, H. Hooghiemstra ${ }^{7}$ and LaACER participants ${ }^{8}$

\begin{abstract}
The Latin American Abrupt Climate Changes and Environmental Responses (LaACER) initiative aims to assess the geographical extent and climatic signature of millennial-scale climate variability in the American tropics and subtropics by combining atmospheric, vegetation and oceanic records, and model simulations.
\end{abstract}

Millennial-scale climate variability such as Dansgaard-Oeschger cycles (Dansgaard et al. 1993) and Heinrich Events (Heinrich 1988) are characterized by a rapid onset and a duration ranging between 200 and 2500 years (Wolff et al. 2010). Open questions relate to the expression of these events in the tropics, the oceanic and atmospheric mechanisms involved, and the interaction with other forcings (e.g. ice volume, greenhouse gases and insolation changes). Modeling these rapid changes in the tropics has proven difficult, partly because modeling targets and constraints from well-documented paleoenvironmental observations of vegetation, fire, precipitation, oceanic processes and biogeochemical cycles remain scarce. Understanding how tropical systems have been affected by, or may have triggered, rapid climate variability in the past is valuable, as the impacts recorded in natural archives might offer some insights into anthro pogenic climate change.

\section{The LaACER initiative}

The INQUA International Focus Group, ACER (Abrupt Climate Changes and Environmental Responses), has promoted considerable advances in the understanding of millennial-scale climate variability and environmental responses. However, in its global synthesis,

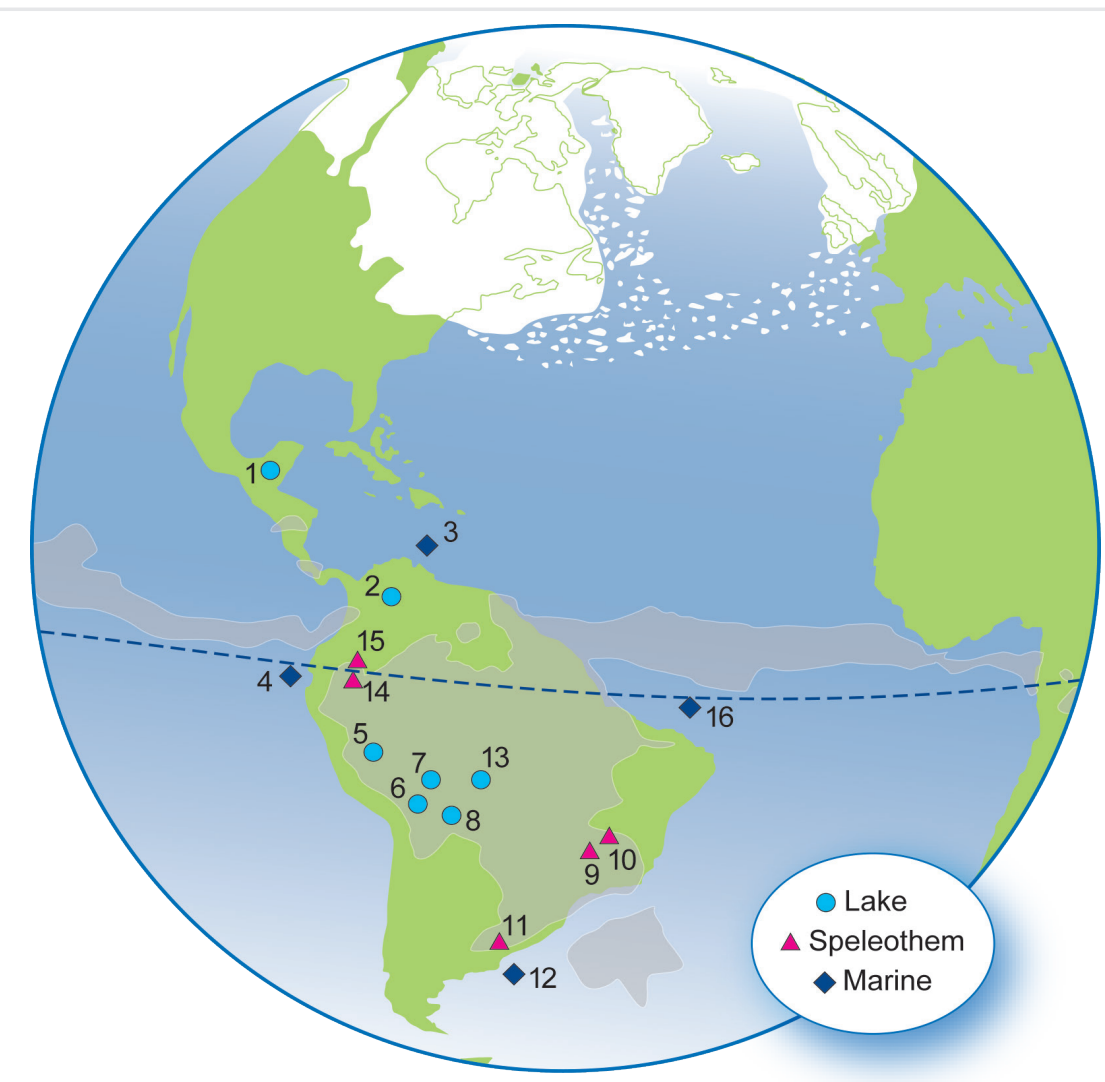

Figure 1: Sampling sites and schematic representation of a Heinrich event. White spots depict iceberg discharge in the Ruddiman belt (Ruddiman 2001). Gray areas represent the boreal-winter configuration of the ITCZ and the SASM based on average January rainfall measured between 1998-2009 (NASA TRMM). Locations of records mentioned in the text are numbered as follows: 1. Peten-Itza (Correa-Metrio et al. 2012; Escobar et al. 2012) 2. Fúquene (Bogotá et al. 2011; Groot et al. 2011; Hooghiemstra 1984), 3. Cariaco (González and Dupont 2009; Peterson et al. 2000), 4. M772-059 (Mollier-Vogel et al. 2013), 5. Junin (Hansen et al. 1994), 6. Titicaca (Baker et al. 2001; Fritz et al. 2010; Paduano et al. 2003), 7. Consuelo (Urrego et al. 2010), 8. La Gaiba (Whitney et al. 2011), 9. Lapa Sem Fim, and 10. Paixão (Strikis et al., pers. comm.), 11. Botuverá (Cruz et al. 2005), 12. GeoB6211-2 (Chiessi et al. 2008, 2009), 13. Chaplin (Mayle et al. 2000), 14. Cueva del Diamante (Cheng et al. 2013), 15. Santiago (Mosblech et al. 2012), 16. GeoB 3104-1 (Arz et al. 1998).

ACER also emphasized the scarcity of millennial-scale paleoclimatic records from the tropical regions (Harrison and Sanchez-Goñi 2010). The Latin American ACER (LaACER) project was conceived to fill this gap. LaACER sits within the Palaeoclimate Commission of INQUA, and has held two workshops to date, both co-supported by PAGES (www.ephe-paleoclimat. com/acer/LaACER.htm).

LaACER's main objective is to improve our understanding of millennial-scale climate variability by investigating its geographical extent and environmental signature in the American tropics and subtropics. Climate in these two regions is influenced by both the Pacific and Atlantic oceans, and by several atmospheric features including the Intertropical Convergence Zone (ITCZ), the North American Monsoon (NAM), the South American Summer Monsoon (SASM), and El Niño-Southern Oscillation (ENSO; Garreaud et al. 2009). The convergence of multiple climatic features in the focus region of LaACER makes it essential for our understanding of the whole climate system.

\section{A consistent chronology}

Understanding the signature of millennial-scale events requires a tight chronological framework that not only permits consistent identification of the events, but also the accurate determination of leads and lags. In their review paper, Sanchez-Goñi and Harrison (2010) define a Heinrich Stadial (HS) as the cold interval triggered by a Heinrich Event (HE). HEs are defined as the periods when large amounts of ice-rafted debris (IRD) were deposited in the Ruddiman belt, a region in the North Atlantic influenced by the Laurentide and Scandinavian ice-sheets (Fig. 1). In absence of the characteristic IRD layers, defining the timing of climate phases related to HEs in the American tropics and subtropics is challenging, but nevertheless critical for advancing our understanding of the processes underlying abrupt climate changes.

As an example, the various chronological approaches used to date the onset of HS1 in the LaACER region result in age discrepancies of up to 800 years. In marine records off the coast of Brazil (GeoB6211-2; Chiessi et al. 2008, 2009; Fig. 1) HS1 is correlated with the chronostratigraphy of HE1 in the North Atlantic (McManus et al. 2004), whereas in the eastern Equatorial Pacific (M772-059; Mollier-Vogel et al. 2013) HS1 is tied to lberian Peninsula records (Bard et al. 2000). Pollen records are correlated with the 
HS chronozones as defined in Sanchez-Goñi and Harrison (2010), others with the interstadials of the North Greenland Ice Core Project or from the lberian Margin (Martrat et al. 2007). Finally, speleothem records are U-Th dated, but the $\mathrm{HS}$ are identified via abrupt stratigraphic changes in the $\delta^{18} \mathrm{O}$ record (Botuverá, Cruz et al. 2005; Santiago, Mosblech et al. 2012; Fig. 1)

Speleothem records show clear abrupt $\delta^{18} \mathrm{O}$ stratigraphic changes that coincide, within age uncertainty, with the timing of radiocarbon-dated Heinrich layers from the Ruddiman belt. These changes can be directly dated with $\mathrm{U} / \mathrm{Th}$, avoiding radiocarbon calibration uncertainties and reservoir corrections. Outside the Ruddiman belt, and specifically in the tropics, the timing of abrupt stratigraphic changes in speleothem records can probably provide the most accurate ages for HS. However, it is important to note that ages derived from speleothem records cannot provide a direct age for $\mathrm{HE}$, as the definition of these climatic events is based on the identification of IRD layers in marine records from the Ruddiman belt. Additionally, assuming synchronicity between high and low latitude records invalidates any analysis of leads and lags.

\section{State of the art}

The LaACER workshops have highlighted well-documented climatic intervals in the American tropics and subtropics, available terrestrial and marine records, and spatial and temporal priorities for future research. The importance of high-resolution records has been illustrated through the development of new speleothem and pollen records that provide some of the best paleoclimate archives from the region. These records reach back to Marine Isotope Stage (MIS) 5 in Botuverá, MIS7 in Lake Fúquene, and MIS8 in the Cueva del Diamante (Fig. 1). Modeling efforts have focused on transient climate simulations and data-model comparisons (Groot et al. 2011; Nace et al. in press). Available paleovegetation records with decadal to centennial resolution are concentrated in the Northern Hemisphere (e.g Fúquene, Peten Itza, Cariaco). In the Southern Hemisphere, paleovegetation records have centennial to millennial resolution (e.g. Junin), and only a handful reach back to MIS 3 (e.g. Consuelo, Titicaca, Chaplin, La Gaiba).

The structure of millennial-scale events in the American tropics and subtropics is one of the main foci of LaACER for the coming years (Fig. 2). A multi-phased structure of HSs in the region is becoming apparent from available records. HS1 in particular has been the focus of paleoceanographic research in the Atlantic (Chiessi et al. 2008) and the Pacific (MollierVogel et al. 2013), and was studied in a series of yet-to-be-published speleothem records from the Lapa Sem Fim and Paixão caves in eastern Brazil (Fig. 1). Overall, records consistently indicate reduced precipitation in the northern American tropics and enhanced precipitation in the southern American tropics during HSs, with two sub-events identified mostly in eastern Brazil (Fig. 2). High-resolution speleothem records from Brazil also reveal two discrete peaks in monsoon activity forming a "double-plunge" structure during the 8.2-ka event (Cheng et al. 2009).

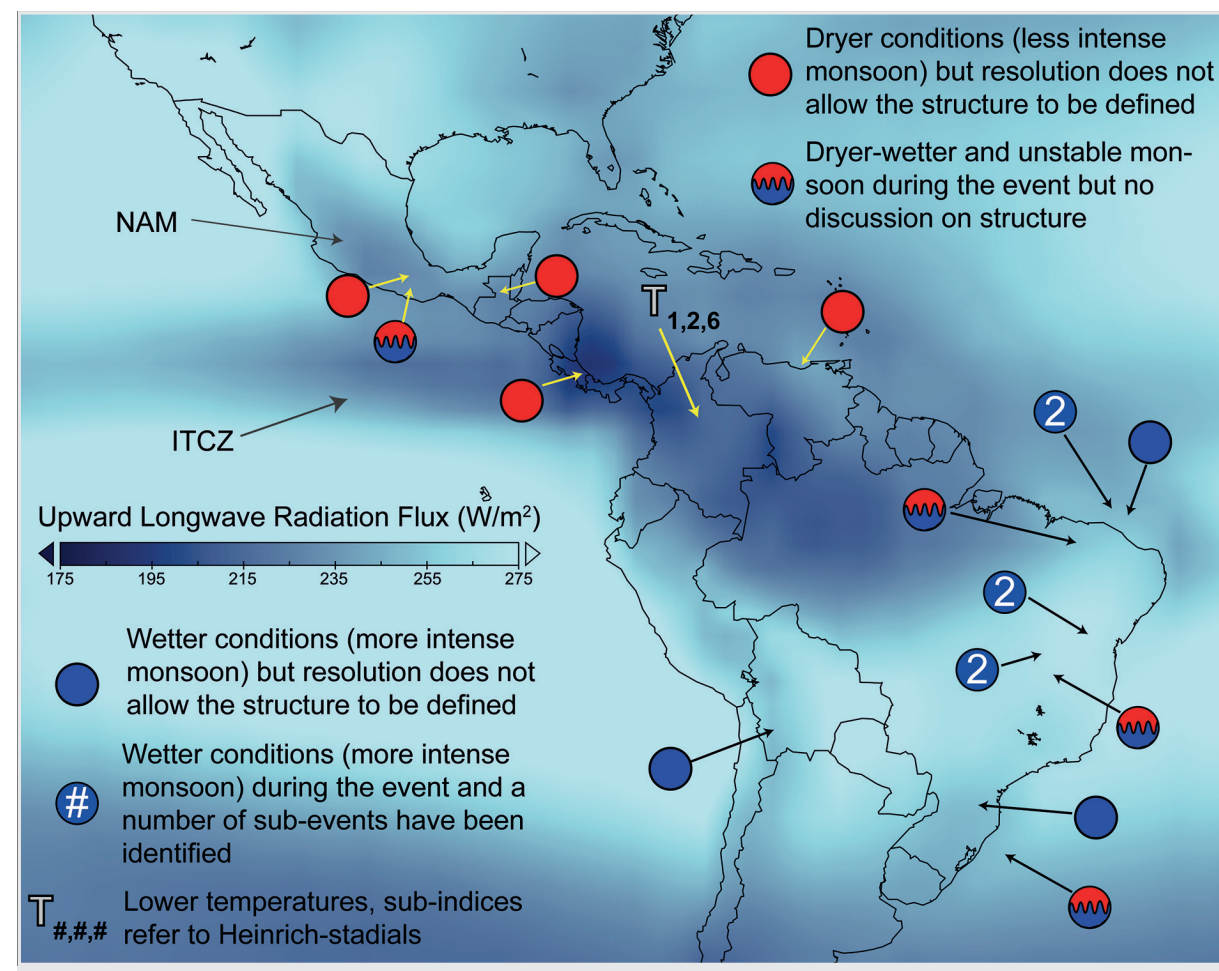

Figure 2: Average outgoing long-wave radiation for the period 1950-2008 (May-November) for the American tropics and subtropics as an indicator for convective activity (NCEP Reanalysis) showing the average position of the ITCZ and the NAM. Circles indicate the structure and signature of millennial-scale North Atlantic cooling stadials at different sites.

\section{Ways forward}

To gain an improved understanding of millennial-scale events in the American tropics and subtropics, LaACER has identified the following research priorities.

- Modeling efforts should prioritize transient and snapshot simulations not only of ocean and atmospheric processes, but also integrate changes in vegetation and fire activity.

- More data-model comparisons will help disentangle the physical processes driving millennial-scale climate variability.

- High-resolution records of vegetation change and fire activity are needed to discern abrupt shifts in environmental conditions.

- The lack of independent proxy records from sedimentary archives for which pollen sequences already exist has been recognized as a limitation, and future work should focus on the generation and integration of such records.

- Existing marine records could possibly be used to extend the sea surface temperature evolution of the Brazil Current beyond HS1.

- New marine records could help characterize the North Brazil Current and its direction during other HSs.

- Marine records with well-preserved terrestrial markers could allow us to directly relate continental and marine changes without chronological ambiguity.

- Future work should also aim to understand ENSO dynamics during HS in the eastern tropical Pacific.

- A priority in the area of atmospheric research is to extend the spatial coverage of paleoclimate data with new high-resolution records that can reveal the dynamics of NAM and SASM.

- Finally, combining speleothem records with vegetation and fire records will reveal more about the dynamics of the ITCZ, NAM and SASM, and enable us to identify the environmental consequences of millennial-scale variability.

\section{AFFILIATIONS}

'Geography, College of Life and Environmental Sciences, University of Exeter, UK

2Ecole Pratique des Hautes Etudes, University of Bordeaux, France

${ }^{3}$ Centro de Geociencias, Universidad Nacional Autónoma de México, Mexico

Escola de Artes, Ciências e Humanidades, Universidade de São Paulo, Brazil

Instituto de Geociências, Universidade de São Paulo, Brazil

${ }^{6}$ Natural History Museum of Utah, Department of Geography, University of Utah, USA

${ }^{7}$ Institute for Biodiversity and Ecosystem Dynamics, University of Amsterdam, The Netherlands ${ }^{8} \mathrm{http} / / /$ ephe-paleoclimat.com/acer/LaACER.htm

\section{CONTACT}

Dunia H. Urrego: D.Urrego@exeter.ac.uk

REFERENCES

Full reference list under:

www.pages-igbp.org/products/magazine/ref2014_2.pdf

Dansgaard W et al. (1993) Nature 364: 218-220

Harrison SP, Sanchez Goñi MF (2010) Quat Sci Rev 29: 2957-2980

Heinrich H (1988) Quat Res 29: 142-152

Sanchez Goñi MF, Harrison SP (2010) Quat Sci Rev 29: 2823-2827

Wolff EW et al. (2010) Quat Sci Rev 29: 2828-2838 